\title{
sciendo
}

DOI 10.2478/sbe-2020-0038

SBE no. 15(2) 2020

\section{HOW DO SOCIALLY RESPONSIBLE HUMAN RESOURCE MANAGEMENT AND VOLUNTARY GREEN BEHAVIOR INFLUENCE ORGANIZATIONAL COMPETITIVENESS?'}

\author{
MD. AFTAB UDDIN \\ Faculty of Human Resource Management, University of Chittagong, Bangladesh
}

\section{REFA AKTER}

Faculty of Management, Rangamati Science and Technology University, Bangladesh

\author{
MD. AL-AMIN
}

Faculty of Business Administration (Management), Mawlana Bhashani Science and Technology University, Bangladesh

\section{SAHIDUR RAHMAN}

Faculty of Management, University of Chittagong, Bangladesh

\section{SHAMEEMA FERDAUSY}

Faculty of Management, University of Chittagong, Bangladesh

\begin{abstract}
:
Environmental sustainability, employees' green behavior, and socially responsible human resource management (SRHRM) are now becoming the key focuses for many organizations all over the world because of the increasing pressures on them to reduce negative environmental impacts of their activities and to maintain environmental issues. Nowadays, organizational sustainability or competitiveness is also depending on how far an organization is responsible for environmental issues. Hence, the study is an attempt to explore the impact of SRHRM and voluntary green behavior (VGB) on organizational competitiveness (OC). We followed the deductive reasoning approach and applied the second generation regression model, such as a structural equation model (SEM) via AMOS. The result shows that SRHRM significantly explains VGB. Further both SRHRM and VGB are significantly predicting organizational competitiveness. One of the critical implications of the study is to use the SRHRM to stimulate the employees towards VGB for enriching their organizational sustainability leading to its competitiveness. The most important limitation of this study is its sample size $(N<200)$, which prevents the generalizability of the results. Thus, the future studies are directed to use more replies for delimiting the causality of the study.
\end{abstract}

1 This paper is the modified version presented in the $1^{\text {st }}$ International Conference On "Finance for Sustainable Growth and Development," organized by the Department of Finance, University of Chittagong, Bangladesh. 
Key words: Socially responsible human resource management, voluntary green behavior, organizational competitiveness

\section{Introduction}

Environmental sustainability and employee green behavior (EGB) have become the key focuses for many organizations all over the world because of the increasing pressure on them to reduce the negative environmental impact of their activities and to comply with environmental rules and regulations (Das, Biswas, Jilani, \& Uddin, 2019). Organizations are also facing severe challenges as environmental issues (climate change, global warming, environmental pollution, energy crisis and so forth) are coming forth with more concerns all over the world which are urging businesses to move towards sustainable operations and green policies (Arulrajah, Opatha, \& Nawaratne, 2016). Organizations are considered as the most significant contributors to climate change and environmental vulnerability, for which many have started to adopt different environmental management techniques. But, only adopting these techniques is not sufficient (Robertson \& Barling, 2013).

Becoming an environmental-friendly organization is largely built on employees' behavior, that is why maintaining employees' green behavior within organizations is now critical to reduce its adverse impacts. Employees' green behavior stimulates cooperation among themselves to make the organization environmentally safe (Paillé, Mejía-Morelos, Marché-Paillé, Chen, \& Chen, 2016). Also, green behavior is closely related to human resource management which can be ensured through shaping a socially responsible human resource management because it is based on the concepts of corporate social responsibility, human resource management ethics, and several employee-oriented human resource practices (Newman, Miao, Hofman, \& Zhu, 2016).

Employee VGB is related to organizational citizenship behavior that renders its support toward organizational, social, and psychological environment (Das et al., 2019). It is a big challenge for the organizations to develop an effective HR policy that supports environmental consideration in attracting, developing, motivating, and retaining required talent people in the business (Vokić, 2015). Organizations with a strong corporate social responsibility and SRHM reputation can have a better opportunity to direct employees at preventing environmental degradation (Newman et al., 2016). Additionally, in line with the understanding of social learning theory, proactive environmental behavior can be endorsed in an organization which has SRHRM. Because it can be attested that if an organization has a green HR policy to prevent decay in environmental, serving employees will feel temptation and compulsion to align with such behavior and attribute it in their actual behavior (Tajfel \& Turner, 1986).

Studies posit that organizations are giving premium on realizing competitiveness through corporate sanctioning on environmental initiatives, such as green human resource management, corporate social responsibilities, etc. (Ayala-Ponce, Vilchis-Vidal, \& PicardAmi, 2018; Bombiak \& Marciniuk-Kluska, 2018). However, little is known regarding the influence of SRHRM on voluntary employees' behavior directed at organizational competitiveness. Globally, it is demanded that organizations will hold their employees 
responsible for protecting the planet (Safari, Salehzadeh, Panahi, \& Abolghasemian, 2018). Thus, the role of SRHRM through enacting environmental policies and corporate strategies for its various operational areas to drive the employees' eco-friendly behavior nursing the earth is not adequately addressed.

Above discussion reveals that less attention has been given in valuing, developing, and measuring socially responsible HRM's contribution to improving organizational competitiveness elsewhere. Therefore, this research gap has motivated the researchers to conduct the present study. This paper aims to contribute in the following ways. First, there is a small study regarding this issue on the influence of SRHRM on employees' environmental behavior, and organizational competitiveness globally. Second, the global ecological concern is increasing progressively, but there are many countries seemed to be environmentally vulnerable. Considering the relative impact of environmental cost on firms and the global economy as a whole, this issue requires adequate attention from policy-makers and academicians. Finally, violation of the environmental problems is a very paramount concern nowadays. Hence, the present study aims at observing how the eradication of these violations through socially responsible human resource management can improve organizational competitiveness.

\section{Literature Review}

\section{Socially Responsible Human Resource Management}

The notion of SRHRM was developed by Shen and Zhu (2011). Socially responsible human resource management is a part of corporate social responsibility that is directed to employees which concentrate on addressing the concerns of employees and also includes recruiting socially responsible staff, rewarding employees' participation in CSR initiatives. Shen and Zhu (2011) introduced three dimensions of SRHRM, namely LCHRM (legal compliance HRM), EO-HRM (employee-oriented HRM) and GF-HRM (general CSR facilitation HRM) on employees' organizational citizenship behavior. LC-HRM refers to the compliance with domestic as well as international rules and regulations, i.e. equal employment opportunity, health and safety, working hours, minimum wage, and the use of child labor and forced labor. EO-HRM involves dealing with employees' personal and family needs that are beyond required by law. GF-HRM refers to the adoption of the policies and practices that encourage organizations and employees in general CSR initiatives (Newman et al., 2016). If employees thought that their organization's HRM is socially responsible, it develops a sense of identification with and creates a moral obligation toward their organizations (Shen \& Zhu, 2011).

\section{Voluntary Green Behavior}

VGB refers to the behaviors that contribute to the environmental sustainability of the organization that exceeds organizational expectations as well as beyond formal corporate requirements (Kim, Kim, Han, Jackson, \& Ployhart, 2014). Organizational practices that are conducive to the environment can be referred to as green organizational 
practices, and employee behaviors that are favorable to the environment can be referred to as green behaviors. Most of the employees' behavior that flourishes environmental sustainability is voluntary. Voluntary green beahvior may include powering down during the non-working period, effective use of office supplies, protecting natural resources and so forth, which will enhance an organization's environmental performance (Kim et al., 2014). Environmental performance of employees can be demonstrated by the degree to which employees are committed to protecting the natural environment (Paillé, Chen, Boiral, \& Jin, 2014).

\section{Organizational Competitiveness}

Every organization wants to maintain a competitive advantage for ensuring their long-term survival in the intensely competitive market. Organizational competitiveness refers to the organizations' ability to cope up with the changing environment and what abilities they have to achieve better results continuously. It is also defined as the potentiality of the organizations that can be used and utilized to achieve organizational goals, make a profit, and exceed customer expectations (Varga, 2017). Some scholars identified 15 factors of organizational competitiveness: strategic alliances, human capital, reliability, knowledge, cost, cultural factors, flexibility, innovation, quality, speed, customer relations, social responsibility, control systems, production techniques, and information and communication technologies (Roman, Piana, de Mello, \& Erdmann, 2012) Some others stated that it depends more on innovative and value-adding abilities (Varga, 2017). Also, organizational competitiveness is termed as the abilities of the organizations offering products and services to consumers that are produced by the standard of social responsibility (Varga, 2017). For these organizations need to have the ability to cope up with the environmental and inner changes.

\section{Hypotheses Development}

\section{Socially Responsible Human Resource Management and Voluntary Green Behavior}

Environmentally sustainable activities turn organizations into the green organization, and it encourages individuals' voluntary green behaviors due to environmentally friendly culture. To be environmentally sustainable organizations, their efforts highly depend on employee voluntary green behavior (Das et al., 2019). Employees voluntary green behaviors are non-work setting and not enforceable by organizational rules and regulations. SRHRM supports socio-psychological environment which promotes employees to act as a citizen of the organization (Newman et al., 2016). Employees perform voluntarily green behavior because they think of themselves as a member of the organization. Following the social identity theory, organizations which maintain SRHRM practices have an environmental friendly identification that encourages employees' voluntary green behavior (Tajfel \& Turner, 1986). Formulating environmentally friendly policies and socially responsible initiatives encourage employees to perform voluntary environmental practices. Thus this study suggests that socially responsible human resource management has a significant favorable influence on voluntary green behavior. 
H1: Socially responsible human resource management significantly predicts voluntary green behavior.

\section{Voluntary Green Behavior and Organizational Competitiveness}

Voluntary green behavior is related to autonomous motivation (Norton, Parker, Zacher, \& Ashkanasy, 2015). Employees may engage in VGB in different ways such as reduction of wastage, reduction of energy consumption, reduction of resource consumption, using recycled paper, and reusable products (Paillé et al., 2016). These play a significant role in conserving organizational resources and energy, as well as creating organizational sustainability. Building organizational sustainability can facilitate in reducing costs, minimizing risks, generating revenues, building a brand image which helps outperform the rivals, thus contribute to competitive advantage. How successful companies can reap competitive advantage over competitors is termed as organizational competitiveness, which mainly depends on innovative and value-adding capabilities (Varga, 2017). Lengyel (2003), cited in Varga (2017), defined organizational competitiveness as the companies' ability to produce long-lasting and profitable products and rendering services that fulfill customer needs on price, quality, and so forth. VGB encourages employees to engage in eco-friendly, innovative activities that increase organizational productivity, and helps to minimize wastage, increase efficiency. Employees involved in VGB are environmentally concerned, more committed to their organization that can work as an essential weapon to gain a competitive advantage over the rivalry. Previous notation suggests that voluntary green behavior has a positive influence on increasing organizational competitiveness.

H2: Voluntary green behavior significantly explains organizational competitiveness.

\section{Socially Responsible Human Resource Management and Organizational Competitiveness}

Organizational policies and practices provide a competitive advantage to the organization by attracting environmentally concerned qualified applicants in the workplace (Das et al., 2019). SRHRM complies with the legal issues benefiting employees, practices employee-centric human resource management, and also renders CSR activities facilitating the environment and stakeholders. In consequences, employees assisted in SRHRM discharge their heightened endeavor to make the organization competitive and sustainable (Newman et al., 2016). Following the social learning theory, SRHRM practices in an organization encourage eco-friendly employees to discharge their eco-friendly behavior, such as cleaner technologies, and re-use of products which have more values to environmentally conscious people for organizational competitiveness (Tajfel \& Turner, 1986). Besides, employees working in SRHRM believe that the organization will endorse their environmental friendly as a part of the organization's CSR activities (Shen \& Benson, 2016). Organizations which have an environmentally friendly policy supported by SRHRM to reduce environmental degradation can build a positive image and add value to their value chain for sustainable organizational competitiveness. Thus we propose that socially responsible human resource has a positive influence on corporate competitiveness. 
H3: Socially responsible human resource management significantly influences organizational Competitiveness.

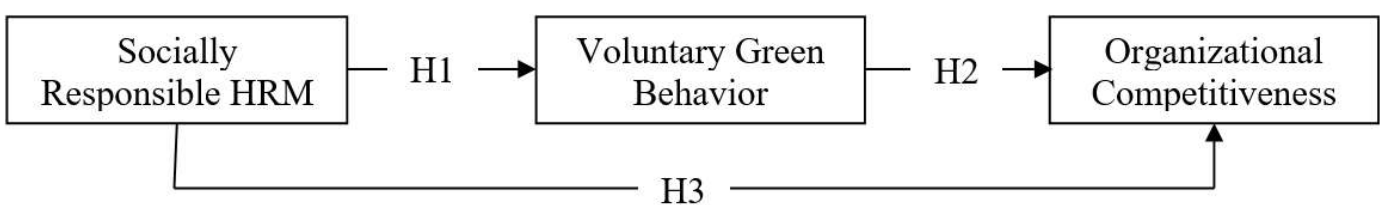

Figure 1: Conceptual Framework of the Research

\section{Research Methods}

Data were collected from the Ready-made garments (RMG). RMG was chosen because of its growing dominance to the total export earnings of Bangladesh. Besides, it is a labor-intensive sector which employs more than two million people directly and indirectly. The study purposefully selected RMGs from Chittagong, the second largest city of Bangladesh. We sent the questionnaire to the human resource department to the randomly selected RMGs from BGMEA list. The package sent to them includes two different sets of questionnaires-one is to report the employees' voluntary green behavior, and another is for reporting the state of the organizational practices such as SRHRM, and organizational competitiveness to prevent the responses from social desirability bias (Azim, Fan, Uddin, Jilani, \& Begum, 2019).

A self-administered survey for the deducting reasoning is followed for positivism paradigm. While delivering the questionnaire, the informants were informed that the research associate would visit them with a time lag of 15 days so that they can fill them up without any bias influence. The authors, with the help of research associates, distributed 250 survey questionnaires; however, 187 completed responses were received with a response rate of 74.80 percent. Further testing the data quality, it reveals that the replies are free from missing values, outliers, same-response biases. Analysis of the respondents' background yields that males dominate the workplace, which contradicts the male-female ratio in the workplace. Since the present study limits respondents to be not less than officer level, thus it prevents the respondents from workers' level in where females dominate the male with a margin of 95 percent. Average age and tenure of the respondents are 33.40 and 7.50 years, respectively. 125 (69 percent) respondents were male from $187(\mathrm{n})$ informants. 50.80 percent of respondents completed a master degree while the others (49.20 percent) were graduates from different universities. Of the RMGs, the study finds those 161 (86.1 percent) small and medium enterprises and 26 (13.9 percent) large enterprises.

The respondents' anonymity was ensured in the questionnaire since personal identification was recorded during the data collection. They were assured that the study would keep the privacy of the respondents, and the observed results will only be used for academic/research sake. Thus the result has prevented the response bias and social desirability bias (Fan, Mahmood, \& Uddin, 2019; Mahmood, Uddin, \& Luo, 2019; Uddin, Mahmood, \& Fan, 2019). Harman singe factor test was performed to find if a single factor 
explains more the 50 percent of the total variance. The estimated result shows that a single factor (VGB) explains 35.75 percent, which is less than 50 percent (47.52 percent) of the total variance (75.23 percent). We also estimated their correlation analyses to observe any correlation exceeding 0.90 . The estimated result exhibits that the highest correlation between any two measures is 0.475 . Thus, no common method of bias or variance issues are reported (Yi, Uddin, Das, Mahmood, \& Sohel, 2019).

\section{Measurement tools}

The study uses survey measures from prior studies which were applied in similar settings anywhere in the world. Interestingly, all the measurement tools used in the study were collected from the Western settings and the procedure suggested by Brislin (1970) were followed for validating the measure to utilize the same construct in other settings or contexts. Items in the survey were measured on a 5-point Likert scale ranging from 1 (Strongly disagree) to 5 (Strongly agree).

\section{Socially responsible human resource management}

Socially responsible human resource management was measured using the scale developed by Shen and Zhu (2011). Sample items were, 'employees in my firm are paid above minimum wages and based on their performance,' 'employees participate in decisions making and total quality management,' and 'my firm rewards employees who contribute to charity, communities and other CSR activities.'

\section{Voluntary green behavior}

Voluntary green behavior is measured by the 7-item instrument developed by Robertson and Barling (2013). Sample items were 'employees put recyclable material (e.g., cans, paper, bottles, batteries) in the recycling bins.', and 'employees take part in environmentally friendly programs (e.g., bike/walk to work day, bring your local lunch day).,'

\section{Organizational competitiveness}

The study adopted the tool developed by Mafabi, Munene, and Ahiauzu (2015). The sample items were 'We serve our customers in a short time,' and 'we can succeed in service delivery amidst resource constraints.'

\section{Findings}

\section{Evaluation of the models}

We use the structural equation model (SEM), a second generation model that integrates all the variables. SEM, through Amos 20, evaluates both the measurement model and structural model simultaneously. Measurement model comprises of crossloading, confirmatory factor analysis, reliabilities, and validity tests, and structural model consists of scrutinizing beta-coefficient, t-statistic, $\mathrm{R}^{2}$, the goodness of fit (GFI) and other statistics. 


\section{Measurement model}

The study evaluates the measurement model using several criteria. First, it scrutinizes the fit indexes. The observed estimates show a perfect fit which is mostly within in the minimum cut off value (Hair Jr., Hult, Ringle, \& Sarstedt, 2014; Hooper, Coughlan, \& Mullen, 2008; Souto, 2015). The SEM using AMOS is sensitive to the sample size $(n=187)$. However, most of the fit index is within the threshold level (Puente-Díaz \& Cavazos-Arroyo, 2017; Shin, Yuan, \& Zhou, 2017).

Table 1. Measurement model fit indices

\begin{tabular}{ccccccc}
\hline Fit-index & $(\mathbf{X}$ /df $)$ & RMR & RMSEA & GFI & TLI & CFI \\
\hline Threshold Value & $<5.0$ & $<0.08$ & $<0.08$ & $>0.80$ & $>0.90$ & $>0.90$ \\
Measurement Model & 1.323 & 0.035 & 0.042 & 0.888 & 0.966 & 0.970
\end{tabular}

Note: RMSEA: lower the better. NFI, TLI, and CFI can range 0-1 (higher the better).

Second, we evaluated the reliability and validity of the measurement model. Reliability is measured with the help of composite reliability, and the validity represents both the convergent validity and discriminant validities (Uddin et al., 2019). The results showed that minimum composite reliability of the measure is 0.869 (SGF) which is above the minimum threshold limit (Hair Jr, Black, Babin, \& Anderson, 2014; Zikmund, Babin, Carr, \& Griffin, 2010). The convergent validity is measured by the average variance explained (AVE, which should be above the minimum cut-off value of 0.50 (Hair Jr, Hult, Ringle, \& Sarstedt, 2014). The estimated results showed that not a single AVE below 0.50. Discriminant validity is measured by the square root of the AVE, which should be more than any correlation with other measures. The estimated results exhibited that the square root of the construct's AVE is more than any correlation with other constructs (Hair Jr, Hult, et al., 2014). Thus, both validities and reliability of the measures are maintained. Finally, we also estimated the cross loading of the items, and it is found that items are rather loaded higher to their corresponding latent variables.

Table 2 : Convergent and discriminant validity

\begin{tabular}{lccccccc}
\hline LV & CR & AVE & EO & VGB & OC & LC & GF \\
\hline EO & 0.891 & 0.672 & $\mathbf{0 . 8 2 0}$ & & & & \\
VGB & 0.939 & 0.689 & 0.367 & $\mathbf{0 . 8 3 0}$ & & & \\
OC & 0.941 & 0.727 & 0.297 & 0.462 & $\mathbf{0 . 8 5 3}$ & & \\
LC & 0.914 & 0.681 & 0.407 & 0.355 & 0.310 & 0.475 & \\
GF & 0.869 & 0.690 & 0.375 & 0.290 & 0.386 & 0.431 & $\mathbf{0 . 8 3 1}$ \\
\hline
\end{tabular}

$\mathrm{LV}=$ latent variable, $\mathrm{CR}=$ composite reliability, $\mathrm{EO}=$ employee orientation, $\mathrm{VGB}=$ voluntary green behavior, OC=organizational competitiveness, LC=legal compliance, GF=general CSR facilitation.

\section{Structural model}

We have divided this section into two sub-sections. First, we assessed the structural model by considering multiple criteria, and second, we will test the hypotheses to arrive at a conclusion the result. While evaluating the structural model, the study first 
checked the model fit $\left(X^{2}(443)=528.00, p=0.000 ; \mathrm{CMIN} / \mathrm{DF}=1.298, \mathrm{GFI}=0.850, \mathrm{RMR}=\right.$ $0.058, \mathrm{CFI}=0.970, \mathrm{TLI}=0.967, \mathrm{IFI}=0.971, \mathrm{RMSEA}=0.040)$. These estimates showed a good fit excepting few indexes due to the small sample size $(n=187)$ (Hair Jr, Black, et al., 2014; Hooper et al., 2008). The study evaluated the $R^{2}$ of dependent variables $\left(R^{2}\right.$ socially responsible human resource management $=0.176 ; R^{2}$ voluntary green behavior $=0.244$; and $R^{2}$ organizational competitiveness $=0.282$ ). We further checked the beta-coefficient to estimate how far exogenous variable has an impact on the endogenous variables [SRHRM $\rightarrow$ VGB $(\beta=$ $0.215, p=0.020) ; \mathrm{VGB} \rightarrow O C(\beta=0.355, p=0.000)$; and SRHRM $\rightarrow O C(\beta=0.269, p=$ $0.000)$ ]. The beta-coefficient of all the significant paths and the $R^{2}$ of all the endogenous variables are close to the minimum threshold of 0.20 (Hair Jr, Hult, et al., 2014).

Following the recommendation of Tenenhaus, Vinzi, Chatelin, and Lauro (2005), we have measured the GoF which equals the square root of the products of the communalities (CM) and the $\mathrm{R}^{2}$ of the endogenous variables. According to Wetzels, Odekerken-Schröder, and Van Oppen (2009, p. 187), $G o F_{\text {small }}=0.10, G o F_{\text {medium }}=0.25$, and $G o F_{\text {large }}=0.36$ provided that the minimum communality of any measure must be above 0.50 (Fornell \& Larcker, 1981). The result showed that the $\mathrm{GoF}=0.399$; and the minimum communality of any measure in the study is $0.651(>0.50)$ which are above the standard (Cohen, 1988; Fornell \& Larcker, 1981; Tenenhaus et al., 2005; Wetzels et al., 2009). Thus, the overall model is fit for the study.

$$
\begin{aligned}
& \text { GoF }=\sqrt{\text { Average } R^{2} * \text { Average Communality }} \ldots \ldots \ldots \ldots \ldots \ldots \text { Equation } 1 \\
& \text { GoF }=\sqrt{0.235 * 0.685} \\
& \text { GoF }=0.401
\end{aligned}
$$

\section{Results}

This study predicts the direct effect of exogenous variables on their endogenous variables. In $\mathrm{H} 1$, we proposed that SRHRM significantly influences the VGB. Study shows that SRHRM significantly influences VGB represented in the estimates $(\beta=0.374, p=$ $0.000)$. Thus, the result supports $H 1$. $H 2$ hypothesized that VGB has a significant effect on OC. The following table also exhibits that the VGB significantly explains $(\beta=0.459, p=$ 0.000 ) OC. Thus the result supports H2. Finally, H3 showed that SRHRM predicts OC. The estimates $(\beta=0.802, p=0.000)$ in the following table reveals that SRHRM significantly influences $\mathrm{OC}$. Therefore, the study supports $\mathrm{H} 3$.

Table 3. Path- relations, and estimates

\begin{tabular}{ccccrrrrr}
\hline Hypothesis & \multicolumn{3}{c}{ Path-Relations } & Estimate & S.E. & C.R. & P \\
\hline H1 & VGB & $<---$ & SRHRM & 0.374 & 0.263 & 3.514 & ${ }^{* * *}$ \\
H2 & OC & $<---$ & VGB & 0.459 & 0.072 & 6.175 & ${ }^{* * *}$ \\
H3 & OC & $<---$ & SRHRM & 0.802 & .244 & 3.288 & .001 \\
\hline
\end{tabular}




\section{Discussion}

The purpose of this study was to explore the extent to which organizational competitiveness is influenced by SRHRM and VGB. In $\mathrm{H} 1$, it was hypothesized that SRHRM significantly influences the VGB, and the study shows that SRHRM significantly influences VGB to predict the estimates $(\beta=0.374, p=0.000)$. Therefore, $\mathrm{H} 1$ is supported because the organization's socially responsible human resource management motivates employees to engage in voluntary green activities. Also, socially responsible reward and recognition system influence employees' voluntary green behavior. Social developmental initiatives by the organizations encourage being more socially responsible toward environmentally friendly activities.

$\mathrm{H} 2$ assumed that VGB has a significant effect on $O C$. The findings revealed that VGB significantly influences $(\beta=0.459, p=0.000) O C$. The result also supports $\mathrm{H} 2$ as organizational productivity increases due to employees' involvement in environmentally friendly activities voluntarily, and that helps minimize wastage, increase efficiency. These employees are environmentally concerned, more committed to their organizations that can assist organizations to gain a competitive advantage over the rivalry. Besides, voluntary green behavior makes an organization sustainable, which increases the social image and corporate reputation.

$\mathrm{H} 3$ demonstrated that SRHRM predicts OC. The estimates $(\beta=0.802, p=0.001)$ also reveal that SRHRM significantly influences OC. Thus, the study supports $\mathrm{H} 3$ because different environmental training programs arranged by the organizations teach employees how to deal with various environmental issues. This type of learning encourages employees to demonstrate superior performance over competitors. Furthermore, when an organization's HRM behaves in a socially responsible way, it develops enthusiastic employees driven toward the firm's task and contextual performance. Henceforth, these task and contextual performances amplify the long-term sustainability of the firm.

\section{Conclusion}

\section{Practical implications}

The present study attempts to understand the inter-relationships among the SRHRM, VGB, and OC. It also aims at finding the impact of SRHRM on VGB, and of SRHRM and VGB on OC. This study makes significant contributions to the field of human resource management and organizational behavior. First, a few types of research have been conducted how SRHRM contributes to enhancing organizational competitiveness. Second, this study will stimulate employees of the organizations to exercise environmentfriendly practices that are a great demand for environmentally concerned customers. Third, SRHRM practices will uphold organizations images toward foreign buyers positively, and a good harmonious relationship will be developed within them. It will minimize the dilemma of the foreign buyers regarding the long-term sustainability of the organizations and undoubtedly will enhance the acceptability of the organizations globally. Finally, RMG sectors can protect the environment from pollution by adopting and practicing SRHRM policies and practices. 


\section{Limitations of the study}

The study is subjected to some constraints which prevent the generalizability of the findings. Firstly, the sample size is very small, which limits the causal inference on the findings. Hence, future researchers might increase the sample size for augmenting the causal inference of the results. Second, we used cross-sectional data, which limits the generalizability of the results. The authors recommend the longitudinal or experimental study to the future researchers for the generalizability of their results. Third, the present study shows that SRHRM predicts VGB, and both SRHRM and VGB explain OC. Interestingly, the mediating effect (indirect effect) of VGB in the relationship between SRHRM and $O C$ is missing. Further, many studies showed that innovation and competitiveness do not happen at a single pace. They are the results of many actors which have been happened at multiple levels with the interactions of many factors. Therefore, it is advised to the future researchers to study the potential impact of indirect effects (moderating and mediating) on these observed relationships.

\section{References:}

Arulrajah, A. A., Opatha, H., \& Nawaratne, N. (2016). Employee green performance of job: a systematic attempt towards measurement. Sri Lankan Journal of Human Resource Management, 6(1), 37-62.

Ayala-Ponce, N., Vilchis-Vidal, A., \& Picard-Ami, M. L. (2018). Corporate environmental responsibility and competitiveness: The maquiladora industry of the Mexican northern borderlands. BUSINESS STRATEGY \& DEVELOPMENT, 1(3), 169-179. doi:10.1002/bsd2.20

Azim, M. T., Fan, L., Uddin, M. A., Jilani, M. M. A. K., \& Begum, S. (2019). Linking transformational leadership with employees' engagement in the creative process. Management Research Review, 0(0), null. doi:doi:10.1108/MRR-08-2018-0286

Bombiak, E., \& Marciniuk-Kluska, A. (2018). Green Human Resource Management as a Tool for the Sustainable Development of Enterprises: Polish Young Company Experience. Sustainability, 10(6), 1739.

Brislin, R. W. (1970). Back-translation for cross-cultural research. Journal of Cross-Cultural Psychology, 1(3), 185-216. doi:https://doi.org/10.1177/135910457000100301

Cohen, J. (1988). Statistical power analysis for the behavioral sciences. Hillsdale, NJ: Lawrence Erlbaum Associates.

Das, A. K., Biswas, S. R., Jilani, M. M. A. K., \& Uddin, M. A. (2019). Corporate Environmental Strategy and Voluntary Environmental Behavior-Mediating Effect of Psychological Green Climate. Sustainability, 11(11), 3123.

Fan, L., Mahmood, M., \& Uddin, M. A. (2019). Supportive Chinese supervisor, innovative international students: a social exchange theory perspective. Asia Pacific Education Review, 20(1), 101-115. doi:10.1007/s12564-018-9572-3

Fornell, C., \& Larcker, D. F. (1981). Evaluating Structural Equation Models with Unobservable Variables and Measurement Error. Journal of Marketing Research, 18(1), 39-50. doi:10.1177/002224378101800104

Hair Jr, J. F., Black, W. C., Babin, B. J., \& Anderson, R. E. (2014). Multivariate Data Analysis: A Global Perspective (7 ed.). London: Pearson.

Hair Jr, J. F., Hult, G. T., Ringle, C. M., \& Sarstedt, M. (2014). A primer on partial least squares structural equation modeling (PLS-SEM) SAGE Publications, Inc. 
Hair Jr., J. F., Hult, G. T. M., Ringle, C. M., \& Sarstedt, M. (2014). A primer on partial least squares structural equation modeling (PLS-SEM): SAGE Publications, Inc.

Hooper, D., Coughlan, J., \& Mullen, M. (2008). Structural equation modelling: Guidelines for determining model fit. Electronic Journal of Business Research Methods, 6(1), 53-60.

Kim, A., Kim, Y., Han, K., Jackson, S. E., \& Ployhart, R. E. (2014). Multilevel Influences on Voluntary Workplace Green Behavior: Individual Differences, Leader Behavior, and Coworker Advocacy. Journal of Management. doi:10.1177/0149206314547386

Lengyel, I. (2003). Verseny és területi fejlödés. Szeged: JATE PRess.

Mafabi, S., Munene, J. C., \& Ahiauzu, A. (2015). Creative climate and organisational resilience: the mediating role of innovation. International Journal of Organizational Analysis, 23(4), 564587. doi:http://dx.doi.org/10.1108/IJOA-07-2012-0596

Mahmood, M., Uddin, M. A., \& Luo, F. (2019). Influence of Transformational Leadership on Employees' Creative Process Engagement: A Multi-Level Analysis. Management Decision, 57(3), 741-764. doi:10.1108/MD-07-2017-0707

Newman, A., Miao, Q., Hofman, P. S., \& Zhu, C. J. (2016). The impact of socially responsible human resource management on employees' organizational citizenship behaviour: the mediating role of organizational identification. The International Journal of Human Resource Management, 27(4), 440-455. doi:10.1080/09585192.2015.1042895

Norton, T. A., Parker, S. L., Zacher, H., \& Ashkanasy, N. M. (2015). Employee green behavior: A theoretical framework, multilevel review, and future research agenda. Organization \& Environment, 28(1), 103-125. doi:10.1177/1086026615575773

Paillé, P., Chen, Y., Boiral, O., \& Jin, J. (2014). The impact of human resource management on environmental performance: An employee-level study. Journal of Business Ethics, 121(3), 451-466.

Paillé, P., Mejía-Morelos, J. H., Marché-Paillé, A., Chen, C. C., \& Chen, Y. (2016). Corporate greening, exchange process among co-workers, and ethics of care: An empirical study on the determinants of pro-environmental behaviors at coworkers-level. Journal of Business Ethics, 136(3), 655-673.

Puente-Díaz, R., \& Cavazos-Arroyo, J. (2017). Creative self-efficacy: The influence of affective states and social persuasion as antecedents and imagination and divergent thinking as consequences. $\quad$ Creativity $\quad$ Research Journal, 312. doi:http://dx.doi.org/10.1080/10400419.2017.1360067

Robertson, J. L., \& Barling, J. (2013). Greening organizations through leaders' influence on employees' pro-environmental behaviors. Journal of Organizational behavior, 34(2), 176194. doi:doi:10.1002/job.1820

Roman, D. J., Piana, J., de Mello, N. R., \& Erdmann, R. H. (2012). Organizational competitiveness factors. Brazilian Business Review, 9(1), 25-42.

Safari, A., Salehzadeh, R., Panahi, R., \& Abolghasemian, S. (2018). Multiple pathways linking environmental knowledge and awareness to employees' green behavior. Corporate Governance: The international journal of business in society, 18(1), 81-103. doi:doi:10.1108/CG-08-2016-0168

Shen, J., \& Benson, J. (2016). When CSR Is a Social Norm:How Socially Responsible Human Resource Management Affects Employee Work Behavior. Journal of Management, 42(6), 1723-1746. doi: $10.1177 / 0149206314522300$

Shen, J., \& Zhu, C. J. (2011). Effects of socially responsible human resource management on employee organizational commitment. The International Journal of Human Resource Management, 22(15), 3020-3035. doi:10.1080/09585192.2011.599951 
Shin, S. J., Yuan, F., \& Zhou, J. (2017). When perceived innovation job requirement increases employee innovative behavior: A sensemaking perspective. Journal of Organizational behavior, 38(1), 68-86. doi:http://dx.doi.org/10.1002/job.2111

Souto, J. E. (2015). Business model innovation and business concept innovation as the context of incremental innovation and radical innovation. Tourism Management, 51, 142-155. doi:https://doi.org/10.1016/j.tourman.2015.05.017

Tajfel, H., \& Turner, J. (Eds.). (1986). The social identity theory of intergroup behavior (Vol. 2). Chicago: Nelson-Hall.

Tenenhaus, M., Vinzi, V. E., Chatelin, Y.-M., \& Lauro, C. (2005). PLS path modeling. Computational Statistics \& Data Analysis, 48(1), 159-205. doi:https://doi.org/10.1016/j.csda.2004.03.005

Uddin, M. A., Mahmood, M., \& Fan, L. (2019). Why Individual Employee Engagement Matters for Team Performance? Mediating Effects of Employee Commitment and Organizational Citizenship Behaviour. Team Performance Management: An International Journal, 25(1/2), 47-68. doi:10.1108/TPM-12-2017-0078

Varga, J. (2017). Bases for organizational competitiveness: Organizational competitiveness status report in Hungary. Economy \& Business Journal, 11(1), 345-358.

Vokić, N. P. (2015). Competitiveness and sustainability of HRM activities in Croatia-CRANET survey results. EFZG working paper series, 15(6), 1-12.

Wetzels, M., Odekerken-Schröder, G., \& Van Oppen, C. (2009). Using PLS path modeling for assessing hierarchical construct models: Guidelines and empirical illustration. MIS Quarterly, 33(1), 177-195. doi:https://doi.org/10.2307/20650284

Yi, L., Uddin, M. A., Das, A. K., Mahmood, M., \& Sohel, S. M. (2019). Do Transformational Leaders Engage Employees in Sustainable Innovative Work Behaviour? Perspective from a Developing Country. Sustainability, 11(9), 2485.

Zikmund, W. G., Babin, B. J., Carr, J. C., \& Griffin, M. (2010). Business Research Method (8th ed.). South-Western, Canada: Cengage Learning. 